\title{
Awards for the Chemical Industries in Italy, from the Responsible Care Program, Examples of Sustainable Development
}

\author{
Ferruccio Trifirò \\ Dipartimento di Chimica Industriale “Toso Montanari” Viale Risorgimento B.4 40136 Bologna, Italy
}

Corresponding Author Email: ferruccio.trifiro@unibo.it

https://doi.org/10.18280/ti-ijes.650110

Received: 16 November 2020

Accepted: 2 February 2021

\section{Keywords:}

wastes, energy, water, biomass, teaching, recycle, safety.

\begin{abstract}
In this note are reported the awards of the Responsible Care program of Federchimica the Italian Association of Chemical Industries attributed to industries that operate in the following strategies of Sustainable Development: the modification of the processes in order to decrease the consume of energy and water and to decrease the amount of produced wastes the transformation of the wastes of the industrial plants and of the products on the market in useful products or new raw materials; the use of biomass as raw material; the teaching of Sustainable Development to students and to employees in order to increase safety in the work. The awards have been attributed to projects from 2017 to 2020 realized in industrial plants in Italy or in the towns where the industries have the plants.
\end{abstract}

\section{INTRODUCTION}

In this paper the awards given to several chemical industries from 2017 to 2020 within the scope of "Responsible Care" program of Federchimica the Association of the Italian Chemical Industries will be reported. The nature of the awarded projects are interesting examples of "Sustainable Development" and "Circular Economy". Responsible Care is a volunteer program of promotion of Sustainable Development of the global Chemical Industry, according to values and behaviours oriented towards safety, health and the environment. This Program was born in Canada in 1984 by the Canadian Chemical Producer Association (CCPA), in 1989 the Program was launched in Europe and in 1992 was introduced in Italy. The "Responsible Care Program" is currently adopted by over 10,000 chemical companies, in more than 70 countries around the world. plays a role of promotion, assistance and connection for all the activities related to sustainable development inside the industries. "Federchimica", every year, assigns the "Responsible Care Award" to three or four companies, in order to recognize virtuous corporate approaches in terms of sustainability and to disseminate good practices among its members. In this paper il will reported the Responsible Care awards of the Italian Federation of chemical industry (Federchimica) attributed in 2017 [1-3], 2018 [4], 2019 [5], and 2020 [6]. The projects of the different awards have been realized in Italy and inside the strategy of Sustainable Development [7, 8].

\section{AWARDS 2017}

2.1 Circular Economy. "Wastes Managements" project of "LyondellBasell"

"LyondellBasell" a multinational world leader in the production and marketing of polyolefins with several plants in
Italy, was awarded for the project "Wastes Management" realized in the plant in Ferrara, for having reduced by $47 \%$ of wastes sent to landfill, thanks to a virtuous waste management system [3, 9]. LyondellBasell in line with the principles of environmental sustainability had investigated the process of recovery and recycling of wastes from the production activities of polymers in the Ferrara site. Through the analysis of the wastes, and their characterization the company has been able to define the potential values of the wastes and to find the several possibilities to place them on the market for their reuse, by identifying qualified and certified suppliers and partners. The results of this project have taken to a reduction of the environmental impact of the pants, with the decrease of $47 \%$ of wastes sent to landfill starting from 2010 and with the consequent reduction of management costs. The company is constantly looking for tools and solutions for improvement of the processes in the strategy of the circular economy model, with the aim of developing new materials with a low environmental impact.

\subsection{The teaching to students some aspects of Sustainable Development. "Kid's Lab" project of "BASF Italia"}

"BASF Italia", a German company arrived in Italy in 2012 and with different plants in many towns, was awarded for the "Kids' Lab" project dedicated to the teaching to students of primary schools the several aspects of water purification through the program "Water loves Chemistry" suitable for children aged 6 to $12[3,10]$. The project is dedicated to the purification of water, to show to the children how chemistry helps in the correct use of this important resource by providing laboratory materials and its own experts to introduce the children to learn the scientific methods of water purification. The Kids' Lab involve the schools of the areas where the production sites of BASF Italia are located. In 2017, around 800 students from the schools of Sasso Marconi and Bologna, Cesano Maderno, Rome, Zingonia and Villanova became 
small chemists by carrying out the following three types of experiments: "Water Purification", "Water Storage" and "Water Research".

In 2018 the project was also implemented in Treviso and another 120 children were able to experience this experience of approaching and raising awareness of sustainability issues. With "Water Purification" experiments children produced dirty water and then gradually purified it from the solids and particles dissolved in it. Through "Water Storage" experiments the children used a mixture of super absorbent polymers and sand, experimenting how infiltration losses in sandy soils are reduced.

Finally, with "Water Research" experiments the students have been engaged in the construction of a "density tower" to observe the behaviour of some plastic spheres, thanks to a solution of water and sugar. Andreas Riehemann CEO of "BASF Italia" commented on the content of this recognition: The Kids' Labs represent excellence from this point of view: first of all for the number of children involved in the area and also for the strong educational nature of the laboratory activities, which create awareness in future generations on sustainability issues.

\subsection{Biofuel from organic wastes. "BioMethER" project of "Sol Group"}

"Sol Group", a multinational group operating in Italy, in 22 other European countries and in Turkey, India and Morocco, has received the award for the project.

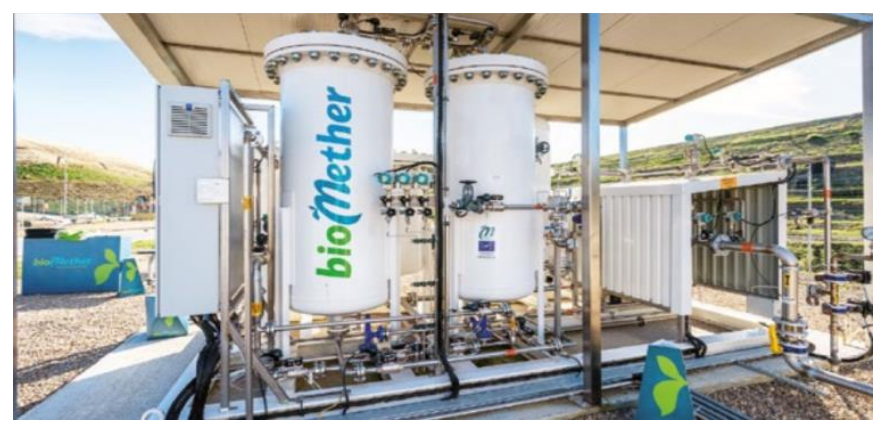

Figure 1. BioMethER pilot plant

BioMethER" (biomethane Emilia Romagna) to produce pure biomethane from wastes realizing a circular economy. The "Sol Group" deals with the production, applied research and distribution of pure industrial and medical gases in the fields of science industrial and medical equipment $[3,11]$.

The BioMethER project with which energy was produced from wastes, was realized with the construction of two pilot plants for the production of pure methane, upgrading biogas obtained from wastes in Figure 1.

One pilot plant was realized at Roncocesi (RE) starting from biogas obtained by the anaerobic digestion of organic matter of different origin (zootechnical effluents, agricultural and agro-industrial by-products, organic fractions of urban waste, purifications sludge, etc.). The second pilot plant was realized in Ravenna starting from biogas obtained of rubbish dump of not dangerous wastes. The project, financed by the "LIFE" program of the European Commission and co-financed by the Emilia-Romagna Region, was developed through biogas purification, with a process called "upgrading". Upgrading technologies remove unwanted components and makes it possible to obtain a gas with a percentage of methane equal to or greater than $95 \%$. Upgrading technologies used by "SIAD "remove components from biogas such as carbon dioxide, water and other compounds that are present in parts per million, such as hydrogen sulfide, ammonia, volatile organic compounds and powders. Upgrading is necessary to make biomethane suitable for the introduction into the natural gas network, with the following technologies of purification: absorption processes with solvents; pressure adsorption processes on beds of solid materials; separation processes with membranes; processes of cryogenic separation by phase transition. The pilot plant uses about $250,000-300,000 \mathrm{~m}^{3}$ of biogas each year that it was previously disposed of with a torch The project allows the production of about 140,000 m3 of biomethane every year, that can be used as fuel for cars avoiding the emission of about 340 tons of $\mathrm{CO}_{2}$. The project is an important example of a circular economy, as it promotes a product that until yesterday was considered a waste and with the results of this project, now it is a resource.

\subsection{Circular Economy." Ecopallets" project of "Versalis"}

"Versalis", the first Italian chemical company in terms of turnover, active in the synthesis of organic raw materials from petroleum, of intermediates, plastics and rubbers, has been awarded for the project "Ecopallets" that it had the objective to demonstrate the possibility to recycle pulper.

wastes, to produce pure paper through paper mills that use recovered paper and after to produce eco-sustainable pallets (named "Life Eco-Pulpast" [3-12].

Inside the recovered paper there are various materials, including mixed plastics, as well as metals, aggregates, cellulose, which cannot be introduced into the paper production cycle and which therefore constitute a waste that today is mainly destined for delivery in landfill or used for energy recovery (Figure 2).

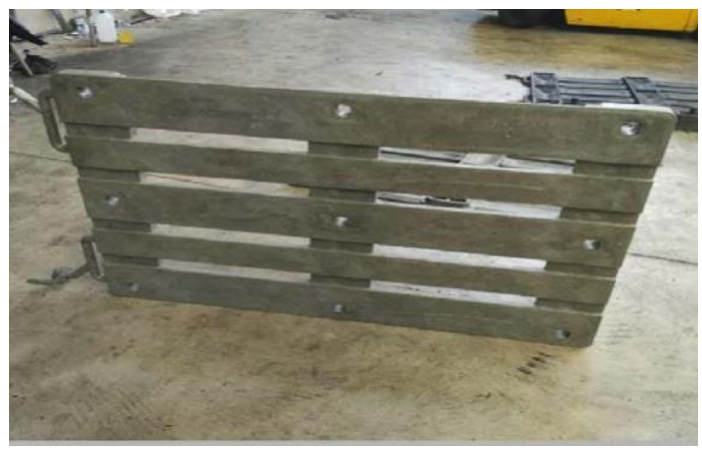

Figure 2. Ecopallet of Versalis

The main idea behind this project has been to realize plastic euro-pallets to be reused by the same paper district that generates the material waste and to create local Circular Economy, which is one main goals of the European Environmental Strategy. This project was funded by the European Community under the "EcoLife" call to use these pallets in the paper production industry, but also in the marketing and storage of plastics, as proposed by Versalis. These recycled plastic eco-pallets will replace the wood-based ones and are recyclable up to 10-15 times, and have eliminated the landfilling of wastes or their energy recovery. Versalis has conducted tests of pallet production on an industrial injection moulding machinery feeding plastic granules from pulper wastes. The project was carried out in Lucca where there is the 
largest paper district in Europe and where about 120 companies operate, which produce about $120,000 \mathrm{t} / \mathrm{y}$ of wastes from the pulpers (pulping plants) to which the waste paper arrives for production of pure paper. Italian industries buy fibrous raw materials in a dry state and the first operation to be carried out in the paper mill is to pulp the fibrous material in the tank of a special machine, called pulper, containing water and which has the purpose of separating the fibrous material into fibers, in the elementary state of plastic. The pulper consists of an impeller equipped with blades placed on the bottom of the pulper itself, the whirling motion created by the impeller causes the sheets of the various pastes used to flake off, reducing them to elementary fibers. Versalis has tested the use of these pallets and will begin to use them for the transport of polyethylene products.

\section{RESPONSIBLE CARE AWARDS IN 2018}

\subsection{A training program for zero accidents. "The safety Academy" project of "Arkema Italia"}

Arkema, the most important chemical group in France active in the specialty chemicals sector, in Italy has 7 production sites and all their products manufactured are distributed in Europe, won the award with the "Safety Academy" project, carried out in all its 7 plants in Italy. The "Safety Academy" is a training project for sharing safety values and objectives in training courses on line for workers, supervisors and other employees [4, 13]. This initiative provides the risk prevention and safety of the staff by a training based on the control of following three complementary aspects: technical, organizational and human aspects. "Safety Academy" is a training program with the objectives of achieving zero accidents by sharing safety values and objectives in a company context. The training includes the discussion of a "Learning Map", a path to achieve the goal of zero injuries and this program has been applied in the USA, Europe and Asia, as well as in Italy, reaching thousands of people with 10 different languages and 40 nations. The "Learning Map" is a path for achieve the goal of zero accidents and in the last three years, the indicators of the accidents of the Group have improved significantly. With a focus on interaction between employees, the facilitators helped participants to initiate dialogues and learn from one another while discussing the priority of the company priority in the creation of a safety-focused culture. The "Strategic Learning Map" session also educated people on Arkema's evolution, by identifying the tools and best practices that were available, toward becoming one of safest industry.

\subsection{The decrease of the consume of energy. "Lighting Revamping" project of "Bracco"}

The "Bracco group", active in the research, development, production and marketing of diagnostic imaging, of medical devices and of administration of contrast medium, received the award for Lighting Revamping" an energy saving project at the Torviscosa plant realized together with Spin, its local company $[4,14]$. Spin at Torviscosa produces Iomeprolo, a contrast agent for radiology, and Iodoftal (intermediate for the production of the Iopamidol a contrast agent in another site). Bracco -Spin, at the Torviscosa site, carried out the "Lighting revamping" project, a new lighting system based on LED lamps equipped with intensity regulator and direction of the luminous flux in Figure 3. An automation system has been inserted in the new lighting system, which can be each LED lamp installed, modify its flow and light intensity based on the input of external sunshine or based on specific needs. The automation system also allows the reporting of electricity consumption thanks to five measuring instruments that calculate consumption using an algorithm. The project led o benefits in terms of reduction of energy consumption, in terms of safety and health on the work by accessed via the company intranet, which is able to recognize improving the visual comfort of the operators especially at night and optimization of preventive maintenance thanks to the early detection of abnormal behavior of each lamp. The new lights, that are over 400 less compared with the previous system, are fitted with brightness intensity and directional beam regulators and the system is entirely automated.

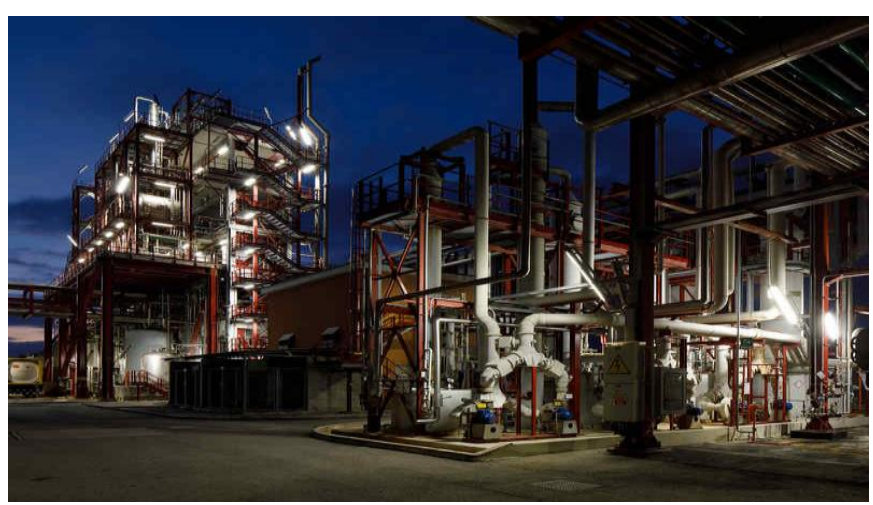

Figure 3. Lighting in a Bracco-Spin plant in Torviscosa

\subsection{Sustainable Development. "Zero Water Consumption" project of "Oréal"}

Oréal, a French cosmetics industry, has a plant in Settimo Torinese, which is the second of the 42 of the group, received the award for the project "Zero waste consumption" for the treatment of the use of water high decreasing of water consumption $[4,15]$. The Settimo Torinese plant is organized into three production units: hair products, mascara and powders for cosmetics and Oréal on the site has implemented a project to eliminate water consumption and since January 2018 the plant has been consuming water only as a raw material in products and not for other uses and all the rest of water is recycled in Figure 4. The excess of produced pure water is sold to Engie, the company that manages the Settimo Torinese district heating network. With these technologies, the production site has more than halved its water consumption and eliminated the quantity of water drawn from its artesian wells. This transformation has occurred in two stages: in the first stage Oréal reduced the water consumption by optimising machinery and manufacturing processes; in the second stage Oréal realized the recycling and reuse of water with ultrafiltering through membranes, which reduces impurities by 85 to $90 \%$, with reverse osmosis, with a biological treatment and with a concentrator.

Thanks to the elimination of leaks and the adoption of a system called "evapoconcentrator" which purifies the water used for washing plants treatment by which water is completely purified and, after being tested, is reused in the manufacturing process. Membrane purification technologies diameter of around 0.03-0.04 microns, removing particles and 
microbial contaminants, but releasing ions and molecules with smaller dimensions. Reverse osmosis allows to separate salts and soluble organic molecule from the water using the principle of reversing the flow of water from a more concentrated solution to a less concentrated one by applying pressure to the concentrated solution. The biological oxidative treatment consists in the biodegradation by microorganisms of all the organic substances present in the water to be purified, up to transforming them into simpler and harmless substances from an environmental point of view. For the biological oxidation several techniques can be used including the more traditional ones as bed systems /leachate, filterachate bed / filter plants and activated sludge plants. This important innovation not only enabled the saving of 38,000,000 litres of water, but also used some of the purified water for the district heating network in Settimo Torinese, helping to meet $20 \%$ of the annual requirement for top-up water for the network. In 2015 Oréal recycled all its wastes, and realized also the complete abatement of $\mathrm{CO}_{2}$ emissions and now Oréal has reduced the consume of water of $54 \%$ relatively to 2005 . To meet the electrical and thermal energy requirement Oreal used photovoltaic panels and a biomass plant, which uses agricultural organic and biological residues.

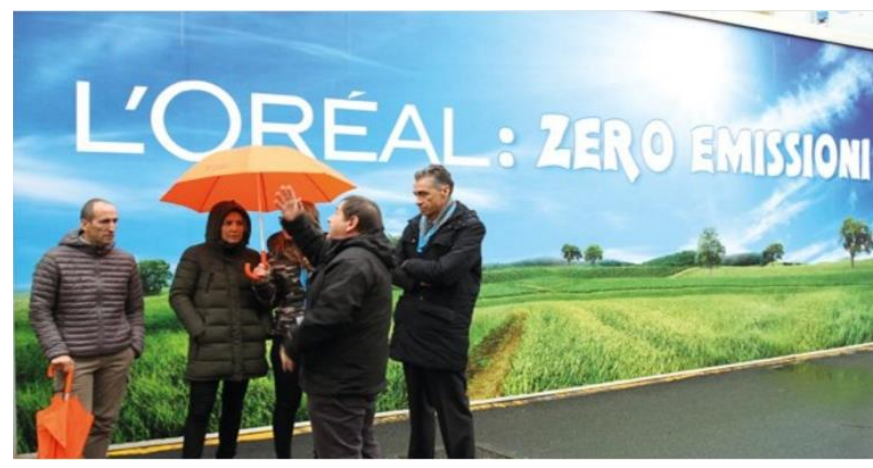

Figure 4. Oreal Zero emission in Settimo Torinese

\section{RESPONDIBLE CARE AWARDS 2019}

\subsection{Circular Economy "Ecofriendly Carbon Dioxides" project of "Siad"}

"Siad" is a company active in the production of industrial, food, special and medical gases, based in Bergamo, received the award for having carried out the "Eco-friendly carbon dioxide" project, carried out at the Solvay plant in Rosignano(Li), where carbonate, solid bicarbonate and organic peroxides are produced $[5,16]$ with emission of $\mathrm{CO}_{2}$ in atmosphere. "Siad" has built a $\mathrm{CO}_{2}$ extraction system from the chimneys of the site's production processes of Solvay, that before it was dispersed into the atmosphere, by using selective solvents and recycling the purified gaseous $\mathrm{CO}_{2}$ in situ to produce carbonates, liquefying a part of it to transport it outside (Figure 5). The direct use on site of carbon dioxide in gaseous form avoided the liquefaction necessary for transport and subsequent evaporation with an energy saving that translates into a further reduction of 7,000 tons of $\mathrm{CO}_{2}$ equivalent per year. The liquefied $\mathrm{CO}_{2}$, on the other hand, was destined for the country's farms to integrate the chlorophyll photosynthesis of greenhouse crops. The plant, which went into operation in 2018 in Rosignano Solvay, made it possible to extract and liquefy the carbon dioxide released by the site's production processes. Thanks to this initiative, up to $5,000 \mathrm{~kg}$ / $\mathrm{h}$ of $\mathrm{CO}_{2}$ emitted are recovered, equivalent to over 40,000 tons per year. Furthermore, the on-site reuse of the raw material allows savings in transport, equal to approximately $1,400,000$ kilometers per year (2,000 tankers and 2,000 trips), with a decrease of approximately one million tons of $\mathrm{CO}_{2}$. The project thus avoided the emission of about $85 \%$ of the quantities of $\mathrm{CO}_{2}$ emitted by Solvay in the past in normal operation and, moreover, allowed the company not to purchase $\mathrm{CO}_{2}$ from the Ferrara site and from Hungary. The project is an example of a circular economy as the project has taken to an economical and technical advantages with an improvement of the environmental impact of the production process.

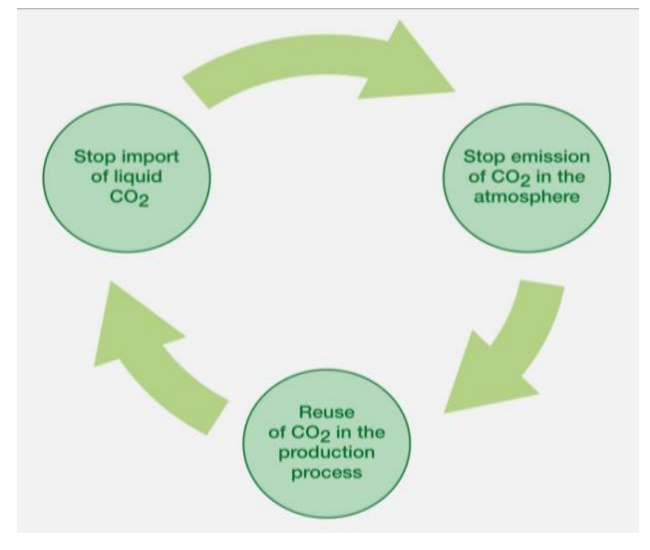

Figure 5. $\mathrm{A} \mathrm{CO}_{2}$ extraction system

\subsection{Cosmetics from biomass. "Certified Sustainability Report" project of "Pink Frogs"}

"Pink Frogs", an Italian cosmetic company founded in 1979 and based in Rozzano (Mi), won the award for being the first Italian cosmetic company to have published a "Sustainability Report" certified according to GRI standards (Global Reporting Initiative), the most accredited international sustainability reporting standard [5, 17]. This was an even more significant result since it was obtained by a medium size industry (SME). The industry is active in the formulations and productions of cosmetics with high standards of quality, safety and respect for the environment, in order to manufacture products with the most sustainable processes and natural ingredients as raw material. The "Pink Frogs' sustainability is based on three fundamental principles: environmental protection, social- responsibility and the economic development of the company. As part of its ISO 14001 environmental management system the industry respects all the principles of environmental protection (precaution, risk prevention and mitigation). Pink Frogs' vision is to develop and produce cosmetics with these principles of respect of the environment and to spread the culture of sustainability through all stakeholders. To support an increasingly "green philosophy" oriented market demand, the industry manufactured products with the most sustainable processes, natural ingredients and active principles. The company carries out measures to prevent, monitor and control the impacts of activities by adopting innovative solutions aimed at reducing the environmental impact and is also committed to promote sustainable behavior by all employees, with seminars, meetings on sustainability. Finally, Pink Frogs has created a "Responsible Use Label" to inform and sensitize the consumer of the environmental benefits that can be achieved with a responsible use of a 
cosmetic. In this label is reported the emission of greenhouse gas, the consume of water and the amount of wastes produces by green processes of "Pink Frogs" and by non-green processes.

\subsection{Lectures to improve air quality. "1.2.3. Respira!" project of "Liquigas"}

"Liquigas", a leading company in Italy in the distribution of LPG (Liquefied Petroleum Gas) and LNG (Liquefied Natural Gas) for domestic, commercial and industrial use, based in Brescia, received the award for promoting the project for the schools "1,2,3 ... Respira!" (Breathe), a creative contest to help to improve air quality. "1,2,3..Reapira" $[5,18]$ is an environmental education project dedicated to students of middle school which the aim to inform and train not only children, but also teachers families, on current issues related to sustainable development and, in particular, to deepen the relationship between air quality and the different types of energy currently available, with a view to sustainable development. Liquigas has provided to the students the information tools necessary to adopt correct behaviors to protect the environment and air quality. At the end of the course, the students were engaged in a competition of ideas in which they presented concrete proposals on the relationship between air quality and the forms of energy currently available in our country. The topics of the courses were as follows: air quality as it is perceived and measured; characteristic sources and forms of energy and properties; fossil fuels and hydrocarbons; renewable? it is not always better; air pollution and geographical areas at risk in Italy.

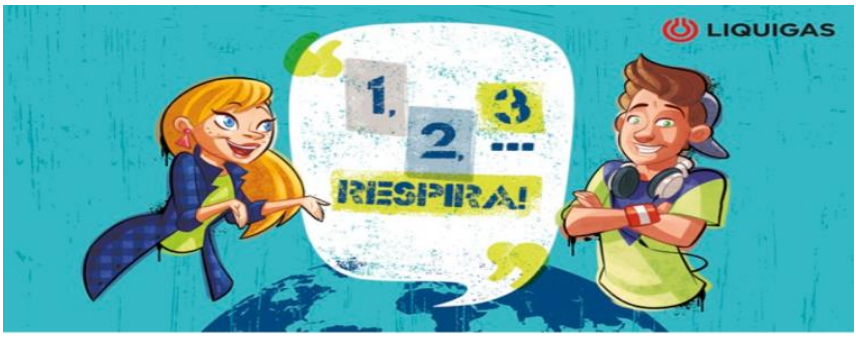

Figure 6. 1,2,3 ... Respira Liquigas

which reliable sites ?; $1,2,3 \ldots$ choose how to breathe in Figure 6. At the end of their educational path students will be able to participate in a competition carried out in a creative way and to provide concrete proposals for solving the problems faced with the theme "Energy and sustainability. The educational path was aimed to explain how solutions can be found to use energy resources to meet our needs in a sustainable way and to have an air quality that does not impact much on the environment and our health. 24,000 students and 455 schools in northern Italy were involved; among these, 5 institutes were awarded with new technical and technological equipment. The students who will be conscious citizens of tomorrow have received the information tools necessary to adopt correct behavior to protect the environment and air quality. In 2020 / 2021 year "1,2,3 ... Respira " 2020/2021 will favor a multidisciplinary approach in the context of the usual school planning and students will be realize the followings presentations: to graphic projects created with the support of the teacher of Art Education, stories and tales elaborated with the teacher of Italian and of song created with the teacher of Music all to explain air quality control.

\section{AWARD 2020}

\subsection{Circular Economy. "MoReTeC" project to LyondellBasell}

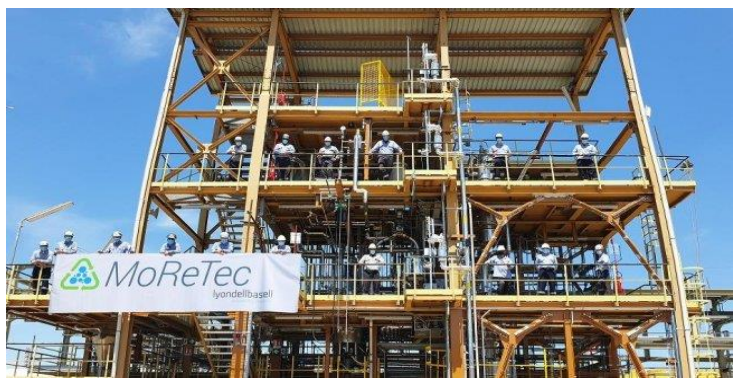

Figure 7. MoReTec pilot plant Ferrara

"LyondellBasell", one of the largest companies in the world in the plastics sector, received the award for the inauguration of the first pilot plant for the molecular recycling of plastics to their original molecules to produce new plastics with the "MoReTeC" project $[6,19]$. The inauguration of pilot plant took place in the Ferrara plant on 8 September 2020. This process aims to recover the plastic wastes that currently goes to landfill or as waste-to-energy plant, creating a molecular recycling process to produce raw materials for the synthesis of plastics (Figure 7). Jim Seward, LyondellBasell Senior Vice President said, "Eliminating plastic wastes from the environment and advancing the circular economy are our society's cornerstones of sustainability. With our advanced recycling technology, we return to the food chain. value larger volumes of (plastic) waste destined to produce new materials for high-quality applications, thus ensuring their value for as long as possible". The process developed by Lyondell-Basell uses catalysts to carry out a pyrolysis reaction, a treatment at $400-500^{\circ} \mathrm{C}$ in the absence of oxygen or with little oxygen to produce liquid products which, by subsequent cracking reaction, can produce raw materials for chemistry and therefore plastics. In Ferrara, the different catalysts and the optimal temperature and contact time were studied and this process will allow the recycling of plastics that currently cannot be recycled such as multilayer films. The pilot plant works using 5-10 kg of wastes and then an industrial plant will be built. The new plastic materials created with LyondellBasell's "MoReTec" technology can also be used for product sectors bound by strict regulatory requirements, such as food packaging and devices for the medical sector. The development of molecular recycling is just one of the three strategies Lyondell-Basell is contributing to the advancement of sustainable solutions for the recycling of plastic wastes. In fact, the company is also involved in mechanical recycling that transforms post-consumer plastic into new plastic granules to be used in applications ranging from household appliances to detergent bottles and suitcases. In addition the company has produced plastics starting from renewable raw materials, such as used cooking oils and vegetable oils, from which it has been possible to create new plastic items, that can be used in the sectors of food packaging, toys and furniture.

\subsection{Circular economy. "recyclable PET" project of "Henkel Italia"}

Henkel Italia Srl, based in Milan with several factories in Italy and active in the sector of products for the home, 
cosmetics and adhesives, won the award for the project "Recyclable PET" for having put plastic bottles for detergents on the market fully recyclable $[5,20]$. The company has been active for years in the recycling of plastics for packaging, which is an important activity for humanity, because packaging protects our products by allowing them to be stored and handled, and it avoids their denaturation and extends their shelf life. Plastic packaging is at the center of media and public opinion because it is accused of polluting the environment and ending its life cycle in the oceans. The biggest problem with packaging is that it usually becomes waste as soon as a consumer finishes using the product and the solution to these problems is to make the existing packaging easier to recycle, and also to use more and more recycled material in new packaging. This idea is at the heart of the circular economy model.

The company in order to recycle PET-based packaging has eliminated the white color of the bottle packaging of a dishwashing liquid, passing to a completely transparent bottle. Transparent PET is among the different types of plastics, the one that gives the most concrete opportunities to start a circular economy, colored (and white materials have limitations and can only be reused in specific cases). The new bottle, in fact, allows more than 600 tons of PET to be introduced into the recycling streams per year. Due to its polymeric structure, PET is an easily recyclable and reusable plastic for many uses and is the only recyclable plastic to date for a new food reuse. PET bottles are the best packaging to contain food liquids, for food protection, for its functionality, practicality, lightness, economy and its $100 \%$ recyclability. Henkel has set the goal for 2025 to reach $100 \%$ recycling of all plastic packaging of its products. Henkel was the first consumer goods company in the world to collaborate with the social enterprise "Plastic Bank" to use the material obtained from plastic wastes found in the sea or on the beaches. Beside the company has worked on the use, as raw material of plastic wastes into products that can be used to produce raw materials for plastics.

\subsection{A sustainable choice of production of cosmetics. "Emotion Light" project of "ROELMI HPC"}

"ROELMI HPC ", born in 2017 from the merger of four independent Italian companies, located in Origgio (Va), operates in the formulation, production and marketing of finished products for the health, beauty and medical devices, obtained the award for the "EMotion Light" project for the production of cosmetic components based on natural raw material (triglyceride-based esters) [5, 21]. These C8-C12 glycerin esters are used in cosmetic formulations thanks to their emollient, solvent, binder and sensorial properties, and they are raw materials from renewable sources. These biomasses used for $100 \%$ are not edible, and therefore are not in competition with the food industry. Furthermore, they are grown on marginal land, unsuitable for biomass for food use, thus allowing the enhancement of the territory. Therefore, "Emotion" products use esters obtained from low environmental impact crops of milk thistle which represent an opportunity for the development of territorial enhancement policies, thanks to the reconversion of over 3500 hectares of marginal areas and the creation of new jobs. alternative products to silicones used previously in cosmetics. All these aspects of this project are symbolic of sustainability. "EMotion Light" is the starting point for the development of a new line of truly sustainable sensory ingredients for the future of the cosmetic market and are recommended for make-up, skin treatment and body care; in particular they are ideal products for pigments, filters, UV and dispersion of powders with high spreadability and with a good absorption rate. Esters are largely employed in cosmetic formulations as softening and smoothing agents and they are used in mostly applications as skin care, make up, sun care and hair care. Nowadays, several categories of esters are in the eye of the storms because of their food chain origin, therefore the producers of esters have two different choices: to reduce environmental impact by using vegetable oils from a controlled supply chain, or to produce by starting from different sources. An industrial plant, completely converted to "green chemistry" allows the creation of highpurity Pelargonic acid (above 98\%) from local crops extract, by local cultivation in marginal lands and the new product is a biodegradable alternative to silicones and it presents wide range of sensorial performances and the product presents a care and make-up applications. In addition, the company in the past in collaboration with Novamont had eliminated the use of microplastics from cosmetics by using non-edible by-products of agri-food processing from the tomato, rice and viticulture supply chain through biotechnological processes with low environmental impact.

\section{CONCLUSIONS}

The description in this note of the several awards attributed chemical industries active in Italy from "Responsible Care" program of Federchimica has evidenced the following aspects useful to realize a Sustainable Development : the modification of the processes in order to decrease the consume of energy and water and to decrease the amount of wastes produced; the transformation of the wastes of the industrial plants and of the products on the market in useful products ; the use of biomass as raw biomaterials; the teaching of sustainable development to students and employees.

The modifications of the preces in order to realize a sustainable development have been the following ones: Lyondell Basell decreased the amount of wastes produced in a plant of production of polyolefins in Ferrara; Bracco decreased the consumption of energy in a plant in Torviscosa of production of intermediates for diagnostic imagines by using a lighting revamping system with Led lamps; Oréal decreased the amount of waste water in the plant of production of cosmetics in Settimo Torinese.

The transformation of wastes to useful products to realize a "Circular Economy" inside the strategy of a "Sustainable Development" were the followings: SOL-GROUP transformed organic wastes obtained from decontamination plants of different towns in biogas by anaerobic fermentation and after in pure methane by purification in several stages of the biogas; Versalis transformed the plastic wastes of the production of paper in Lucca in ecopallets; SIAD transformed in Rosignano in a plant od production of sodium bicarbonate of Solvay the $\mathrm{CO}_{2}$ emitted in air in pure $\mathrm{CO}_{2}$ to recycle in the plant and to liquefie to be sold outside; LyondellBassel transformed plastic wastes by chemical modification in raw materials to produce plastics; Henkel produced PET used in bottle for detergent completely recyclable.

The use of biomass as raw material to decrease the amount of emission of $\mathrm{CO}_{2}$ and to increase the safety of products has been realized by: Roelmi HPC by replacing the use of silicones 
in the production of cosmetics with triglycerides obtained by local cultivation in marginal lands; Pink Frogs produce cosmetic products using natural ingredients, and this choice allowed the industry to be the first Italian cosmetic industry to have reported a "Sustainability Report" with an international certification.

The teaching of sustainable development and sustainable behaviour have been realized by: "Basf Italia" through teaching to students of primary schools of towns where they have plants the seral aspects of purification of water; Liquigas has realized lecture for students on the quality of air related to the current different available energy; Arkema has realized lectures for their workers ad and employees of all aspects of" Sustainable Development" in order to increase the safety in the production plants.

\section{REFERENCES}

[1] Responsible Care - International Council of Chemical Associations (icca-chem.org). https://iccachem.org/focus/responsible-care/.

[2] Premio Responsible Care 2020. http://www.federchimica/webmagazine/dettaglionews/2020/06/10/aperto-lecandidature-alpremioresponsible- care-2020.

[3] Trifirò, F. (2017). Premi all'industria per l'economia circolare e per la chimica spiegata ai bambini. La Chimica e L'Industria Newsletter 4(9): 4-9.

[4] Trifirò, F. (2018). Sostenibilità ed Economia Circolare per il Pianeta. I vincitori del premio "Responsible Care" di Federchimica. La Chimica e l'Industria Newsletter 5(8): 29-33.

[5] Trifirò, F. (2020). Esempi industriali di uno Sviluppo Sostenibile. La Chimica e l'Industria Newsletter, 7(1): 45.

[6] Responsible Care: Il bilancio di sostenibilità dell'industria chimica in Italia (federchimica.it). http://www.federchimica/web magazine/dettaglionews/2020/11/09/26-responsible-care-2020.

[7] Trifirò, F. (2019). Fuels from biomass, TECNICA ITALIANA-Italian Journal of Engineering Science, 63(1): 86-93. https://doi.org/10.18280/ti-ijes.630112

[8] Bardi, U., Perissi, I., Csala, D., Sgouridis, S. (2016). The sower's way: A strategy to attain the energy transition, International Journal of Heat and Technology, 34(S2): S263-S265. https://doi.org/10.18280/ijht.34S211
[9] Grow Sustainable Solutions |LyondellBasell https://www.lyondellbasell.com/en/sustainability/growsustainable-solutions/.

[10] Little scientist at BASF Kids' Lab. https:/www.basf.com/cn/en/medium/BASF/Informatio ns/Inspirations/Little-scientists-at BASF-Kids-Labhotmail.

[11] Il gruppo SIAD per la filiera del biometano. https:/www.thesiadgroup.com/documents/104367/0/sias _catalogo_biometano_ecomondo_it.pdf/b0515fe6-5f81$\overline{\mathrm{d}} 589-5 \mathrm{~b} 1 \overline{8}-86 \mathrm{c} 537 \mathrm{~d} 6 \overline{\mathrm{d}} \mathrm{af3}$ (thesiadgroup.com).

[12] LIFE -Eco-Pulplast. http://www.life-ecopulplast.eu//.

[13] Arkema celebrates World Day for Safety and Health at Work. https://www.evatane.com/en/news/Arkemacelebrates-World-Day-for-Safety-and-Health-at-Work.

[14] The Torviscosa light engineering revamping project wins the Federchimica Responsible Care award (bracco.com). https:/www.bracco.com/en/news/torviscosa-lightengineering-revamping-project-wins-federchimicaresponsible-care-award.

[15] Oceans apart: Why businesses need to embed water efficiency across departments. https:/www.edie.net/library/Oceans-apart--Whybusinesses-need-to-account-for-the-water-energynexus/6763.

[16] $\mathrm{CO}_{2}$ Ecofriendly: SIAD innovative project in Rosignano. https://www.federchimica .it/ docs/default-source / default-document -library/S-gamba-siad. Pdf?sfvrsn=7ace4793_0.

[17] Pink Frogs for the planet future. https://pinkfrogs.it/wpcontent/uploads/2020/01/Comunicato-Energia-FontiRinnovabili-en.pdf.

[18] Liquigas launches “ $1,2,3 \ldots$ RESPIRA!" project for schools to focus on sustainability and future environmental impact - SHV Energy. https://www.shvenergy.com/our-impact/impactstories/sustaining-the-environment/liquigas-launches123respira-project.

[19] Advancing a Circular Economy | LyondellBasell. htpps://www.lyondellbasell.com/en/sustainability/advan cing-a circular--economy/.

[20] Creating Smarter Packaging (henkel.com). https//www.henkel.com/sustainability/positions/packagi ng.

[21] EMotion ${ }^{\circledR} \quad-\quad$ ROELMI https://www.roelmihpc.com/pEMotion ${ }^{\circledR} \quad-\quad$ ROELMI HPC ortfolio/emotion/. 